\title{
Sleep Quality, Day Time Sleepiness and Academic Performance in First Year Medical Students
}

\author{
Pradeep C. Thomas ${ }^{1}$, Bindu Sundar ${ }^{2}$ \\ ${ }^{1}$ Associate Professor, Department of Physiology, Government Medical College, Kottayam, Kerala, India. \\ ${ }^{2}$ Associate Professor, Department of Physiology, Government Medical College, Thiruvananthapuram, Kerala, India.
}

\section{ABSTRACT}

\section{BACKGROUND}

Sleep deprivation would result in sleepiness during learning activities, with impairment of cognitive abilities and psychological wellbeing. Medical training, with its immense workload in a highly stressful environment, makes students especially vulnerable to poor sleep. This study evaluated the impact of sleep quality and related factors on academic performance in medical students of first academic year.

\section{METHODS}

This is a cross sectional study. 138 students in the first academic year of MBBS course in Govt. Medical College, Kottayam were enrolled as the study group. Assessment of sleep quality was based on scores of Pittsburgh Sleep Quality Index [PSQI]. Epworth Sleepiness Scale [ESS], a validated self-reported questionnaire, was used to assess excessive daytime sleepiness. Internal assessment marks scored by each student in the examinations conducted within 30 days prior to filling the questionnaire, was used to examine the relationship between academic performance, sleep quality and daytime sleepiness.

\section{RESULTS}

Quality of sleep was assessed both subjectively and objectively. It did not show statistically significant association with level of academic performance of the students. Significant association was found between sleep disturbance and level of academic achievement. Majority of students with good academic performance were found to have normal day time sleepiness, although the association was not statistically significant.

\section{CONCLUSIONS}

Sleep deprivation adversely affects the academic performance of medical students of first academic year. Awareness regarding good sleep hygiene need to be created among students at the institutional level.

\section{KEYWORDS}

Sleep Quality, Sleepiness, Academic, Medical
Corresponding Author:

Dr. Bindu Sundar,

Associate Professor,

Department of Physiology,

Government Medical College,

Thiruvananthapuram-695011,

Kerala, India.

E-mail: bindusundar.april@gmail.com

DOI: $10.14260 /$ jemds/2019/638

Financial or Other Competing Interests: None.

How to Cite This Article:

Thomas PC, Sundar BJ. Sleep quality, day time sleepiness and academic performance in first year medical students. J. Evolution Med. Dent. Sci. 2019;8(39):2934-2938, DOI: $10.14260 / \mathrm{jemds} / 2019 / 638$

Submission 06-08-2019,

Peer Review 15-06-2019,

Acceptance 21-09-2019,

Published 30-09-2019. 


\section{BACKGROUND}

Sleep is an active, repetitive and reversible behaviour serving several different functions, such as repair and growth, learning or memory consolidation, and restorative processes.(1) Several studies have reported that the prevalence of sleep complaints is more among medical students than among the general population.(2) Cognitive abilities including consolidation and encoding of memories are very important for medical education, because medical students need to learn a lot of Greco-Latin medical terminology, understand and retain a substantial amount of complex factual knowledge within short period of time and apply them to different situations occurring during almost a lifetime of professional practice.(3)

The sleep-wake cycle of medical students is characterized by insufficient sleep duration, delayed sleep onset, and occurrence of napping episodes during the day.(4) Four fundamental sleep characteristics influence academic performance: sleep quantity, sleep quality, sleep regularity, and sleep phase scheduling.(5) Cognitive functions related to academic such as memory consolidation, learning, decision making and critical thinking are all related with adequate sleep.(6) The consolidation of higher-order implicitly learned information is linked to the rapid eye movement (REM) stage of sleep.(7) As REM sleep episodes tend to increase in the last third of the night, sleep deprivation may significantly reduce the percentage of REM sleep. Sleep deprivation may impair memory and decision making.(8) Poor sleep may indirectly affect performance by increasing depression, decreasing motivation and compromising health.(9)

\section{Aims and Objectives}

1. To find out whether there is any association between the quality of sleep of first year medical students assessed by Pittsburgh Sleep Quality index (PSQI) and their academic performance.

2. To find the association between subjectively assessed sleep quality of first year medical students and their academic performance.

3. To find out whether there is any association between the daytime sleepiness of medical students assessed by Epworth Sleepiness Scale (ESS) and their academic performance.

\section{METHODS}

\section{Study Design}

Cross sectional study.

\section{Sample Size}

The study group comprised of 138 students [67 males and 71 females] of first year MBBS in Govt., Medical College, Kottayam. All 150 students of first year MBBS were enrolled, out of which twelve were excluded based on exclusion criteria.

\section{Inclusion Criteria}

Medical students of the first academic year, who gave voluntary consent and filled up the questionnaire forms.

\section{Exclusion Criteria}

- Any diagnosed mental illness.

- Use of medication capable of depressing or stimulating brain function. [Adrenergic agonists, adrenergic blockers, antihistamines, antiepileptics, opioid analgesics, anorexiants, psychiatric medication).

- Drug abuse (Cannabis, cocaine, amphetamine, opioids, ephedrine, diazepam etc.)

- Habitual intake of alcohol and those presently under influence of alcohol.

- Habitual smoking.

- Habitual pan chewers.

- Diseases of thyroid gland.

- Students who gave incomplete data.

\section{Study tools}

1. Questionnaire for presence of exclusion criteria

\section{Sleep Quality}

Assessment of sleep quality was based on scores of Pittsburgh Sleep Quality Index [PSQI].The questions related to the subject's usual sleep habits during the past month. Most accurate reply for majority of days and nights in the past month were recorded and scored. The questionnaire also compiled information on the subject's own rating of his or her overall sleep quality (Subjective sleep quality).

PSQI

Minimum Score $=0$ (better); Maximum Score = 21 (worse) Interpretation: TOTAL $<5$ associated with good sleep quality. Total $>5$ associated with poor sleep quality.

Good quality (PSQI score $\leq 5$ ), Poor quality (PSQI score $>5$ )

Daytime Sleepiness

Scores of the Epworth Sleepiness Scale[10] [ESS, 1997 version], a validated self-reported_questionnaire was used to assess daytime sleepiness. The scale contains questions as to whether the subject fell asleep or dozed off in different situations: sitting and reading, watching TV, sitting inactive in public places, as a passenger in a car for 1 hour without a break, lying down to rest in the afternoon when circumstances permit, sitting and talking to someone, sitting quietly after a lunch without alcohol, and in a car while stopped for a few minutes in traffic, with an aggregate score of 0 to 24 .

\section{ESS Scores}

0 to 5: Lower normal Daytime sleepiness (DTS),

6 to 10: Higher normal DTS

11 to 12: Mild excessive DTS

13 to 15: Moderate excessive DTS

16 to 24: Severe excessive DTS.

\section{Academic Performance}

Marks scored by the students in the final sessional theory examination which was conducted within 30 days prior to filling of the questionnaire was used to assess academic performance. 


\section{Methodology}

The study was conducted in first year medical students of academic year 2016, after obtaining approval from Institutional Review Board and Ethics committee of Govt. Medical college, Kottayam [IRB No.121/2017 dated $31 / 10 / 17$ ] for a period of six months from $2 / 11 / 2017$. Students were briefed on the purpose and procedure of the study, and all students who gave informed consent were administered the questionnaire for exclusion of conditions as specified. After exclusion of students based on criteria, PSQI and ESS questionnaire forms were administered to all other students. Subjects were explained the importance of filling the questionnaire honestly and accurately for ensuring the outcome of the study. Duly filled forms were collected, and Global PSQI score and total ESS score calculated for each student. Internal assessment marks scored by each student, in the theory sessional examination conducted within 30 days prior to filling the questionnaire were compiled for analysis of academic performance. Grading of level of academic performance was taken as Poor for marks $\leq 49 \%$, Satisfactory for $50-64 \%$ and Good for $\geq 65 \%$. The global PSQI scores, total ESS scores, and the marks scored were subjected to statistical analysis for association among each other. Confounding effect of gender, if any, was searched for.

\section{Statistical Analysis}

Data was entered in Microsoft Excel and Statistical analysis was performed using Statistical Package for Social Sciences (SPSS version 22.0).Data was represented in appropriate tables and charts in the form of frequency and percentages. Chi-square test was employed to find out statistical association as required. For all statistical evaluations, probability of value $<0.05$ was considered significant.

\section{RESULTS}

\begin{tabular}{|c|c|c|c|c|c|}
\hline $\begin{array}{c}\text { Sleep } \\
\text { Quality } \\
\text { Based on } \\
\text { PSQI }\end{array}$ & & \multicolumn{3}{|c|}{$\begin{array}{c}\text { Level of Academic } \\
\text { Performance }\end{array}$} & \multirow{2}{*}{ Total } \\
\cline { 3 - 5 } & & Poor & Satisfactory & Good & \\
\hline $\begin{array}{c}\text { Good sleep } \\
\text { quality }\end{array}$ & Frequency [\%] & $49(57.0 \%)$ & $32(37.2 \%)$ & $5(5.8 \%)$ & $86(100.0 \%)$ \\
\hline $\begin{array}{c}\text { Poor sleep } \\
\text { quality }\end{array}$ & Frequency (\%) & $32(61.5 \%)$ & $15(28.8 \%)$ & $5(9.6 \%)$ & $52(100.0 \%)$ \\
\hline Total & Frequency (\%) & $81(58.7 \%)$ & $47(34.1 \%)$ & $10(7.2 \%)$ & $138(100.0 \%)$ \\
\hline Table 1. Distribution of Study Participants according to Sleep Quality \\
and Academic Performance \\
\hline$\chi^{2}=1.42, \mathrm{p}=.491 ; \mathrm{p}>0.05 ; \mathrm{df}=2$. \\
\hline
\end{tabular}

No significant association was found between Quality of sleep assessed by PSQI score and Level of academic achievement in the study group. However, percentages reveal that $61.5 \%$ with poor sleep quality were poor academic performers, while $43 \%(37.2 \%+5.8 \%)$ of students with good sleep quality showed satisfactory to good performance. No significant association was found between level of daytime sleepiness and academic achievement. No significant association was obtained between Subjective sleep quality of students and their academic performance. Significant association was found between sleep disturbance and academic performance in the study group.

\begin{tabular}{|c|c|c|c|c|c|}
\hline \multirow{2}{*}{$\begin{array}{l}\text { Day time Sleepiness } \\
\text { Based on ESS }\end{array}$} & & \multicolumn{3}{|c|}{$\begin{array}{l}\text { Level of Academic } \\
\text { Performance }\end{array}$} & \multirow{2}{*}{ Total } \\
\hline & & Poor & $\begin{array}{c}\text { Satisfac } \\
\text { tory }\end{array}$ & Good & \\
\hline $\begin{array}{l}\text { Lower Normal Daytime } \\
\text { Sleepiness }\end{array}$ & Frequency (\%) & $6(46.2 \%)$ & $6(46.2 \%)$ & $1(7.7 \%)$ & $13(100.0 \%)$ \\
\hline $\begin{array}{l}\text { Higher Normal Daytime } \\
\text { Sleepiness }\end{array}$ & Frequency (\%) & $49(62.0 \%)$ & $24(30.4 \%)$ & $6(7.6 \%)$ & $79(100.0 \%)$ \\
\hline $\begin{array}{l}\text { Mild Excessive Daytime } \\
\text { Sleepiness }\end{array}$ & Frequency (\%) & $14(58.3 \%)$ & $8(33.3 \%)$ & $2(8.3 \%)$ & $24(100.0 \%)$ \\
\hline $\begin{array}{l}\text { Moderate Excessive } \\
\text { Daytime Sleepiness }\end{array}$ & Frequency (\%) & $9(52.9 \%)$ & $7(41.2 \%)$ & $1(5.9 \%)$ & $17(100.0 \%)$ \\
\hline $\begin{array}{c}\text { Severe Excessive Daytime } \\
\text { Sleepiness }\end{array}$ & Frequency (\%) & $3(60.0 \%)$ & $2(40.0 \%)$ & $0(0.0 \%)$ & $5(100.0 \%)$ \\
\hline Total & Frequency (\%) & \begin{tabular}{|c|}
81 \\
$(58.7 \%)$ \\
\end{tabular} & $\begin{array}{c}47 \\
(34.1 \%) \\
\end{array}$ & $\begin{array}{c}10 \\
(7.2 \%) \\
\end{array}$ & $\begin{array}{c}138 \\
(100.0 \%) \\
\end{array}$ \\
\hline \multicolumn{6}{|c|}{$\begin{array}{c}\text { Table 2. Distribution of Study Participants according to Day Time } \\
\text { Sleepiness and Academic Performance }\end{array}$} \\
\hline \multicolumn{6}{|c|}{$\chi^{2}=2.56, p=.959 ; p>0.05 ; d f=8$} \\
\hline
\end{tabular}

\begin{tabular}{|c|c|c|c|c|c|}
\hline \multirow{2}{*}{$\begin{array}{c}\text { Subjective } \\
\text { Sleep } \\
\text { Quality }\end{array}$} & & \multicolumn{3}{|c|}{$\begin{array}{l}\text { Level of Academic } \\
\text { Performance }\end{array}$} & \multirow{2}{*}{ Total } \\
\hline & & Poor & $\begin{array}{l}\text { Satisfie } \\
\text { d }\end{array}$ & Good & \\
\hline Very Good & Frequency (\%) & $22(55.0 \%)$ & $16(40.0 \%)$ & $2(5.0 \%)$ & $40(100.0 \%)$ \\
\hline Fairly Good & Frequency (\%) & $47(60.3 \%)$ & $24(30.8 \%)$ & $7(9.0 \%)$ & $78(100.0 \%)$ \\
\hline Fairly Bad & Frequency (\%) & $10(62.5 \%)$ & $5(31.3 \%)$ & $1(6.3 \%)$ & $16(100.0 \%)$ \\
\hline Very Bad & Frequency (\%) & $2(50.0 \%)$ & $2(50.0 \%)$ & $0(0.0 \%)$ & $4(100.0 \%)$ \\
\hline Total & Frequency (\%) & $\begin{array}{c}81 \\
(58.7 \%)\end{array}$ & $\begin{array}{c}47 \\
(34.1 \%)\end{array}$ & $\begin{array}{c}10 \\
(7.2 \%)\end{array}$ & $\begin{array}{c}138 \\
(100.0 \%)\end{array}$ \\
\hline \multicolumn{6}{|c|}{$\begin{array}{c}\text { Table 3. Distribution of Study Participants according to Subjective } \\
\text { Sleep Quality and Academic Performance }\end{array}$} \\
\hline & $p>0.05$ & & & & \\
\hline
\end{tabular}

\begin{tabular}{|c|c|c|c|c|c|}
\hline \multirow{2}{*}{$\begin{array}{c}\text { Sleep } \\
\text { Disturbance }\end{array}$} & \multicolumn{3}{|c|}{$\begin{array}{c}\text { Level of Academic } \\
\text { Performance }\end{array}$} & \multirow{2}{*}{ Total } \\
\cline { 3 - 5 } & & Poor & $\begin{array}{c}\text { Satisfact } \\
\text { ory }\end{array}$ & Good & \\
\hline 0 & Frequency (\%) & $7(77.8 \%)$ & $0(0.0 \%)$ & $2(22.2 \%)$ & $9(100.0 \%)$ \\
\hline 1 to 9 & Frequency (\%) & $71(56.8 \%)$ & $46(36.8 \%)$ & $8(6.4 \%)$ & $125(100.0 \%)$ \\
\hline 10 to 18 & Frequency (\%) & $3(75.0 \%)$ & $1(25.0 \%)$ & $0(0.0 \%)$ & $4(100.0 \%)$ \\
\hline Total & Frequency (\%) & $\mathbf{8 1 ( 5 8 . 7 \% )}$ & $\mathbf{4 7}(34.1 \%)$ & $\mathbf{1 0}(7.2 \%)$ & $\mathbf{1 3 8}(\mathbf{1 0 0 . 0} \%)$ \\
\hline \multicolumn{6}{|c|}{ Table 4. Distribution of Study Participants according to Sleep } \\
Disturbance and Academic Performance \\
\hline$\chi^{2}=9.75, \mathrm{p}=.045 ; \mathrm{p}<0.05 ; \mathrm{df}=4$.
\end{tabular}

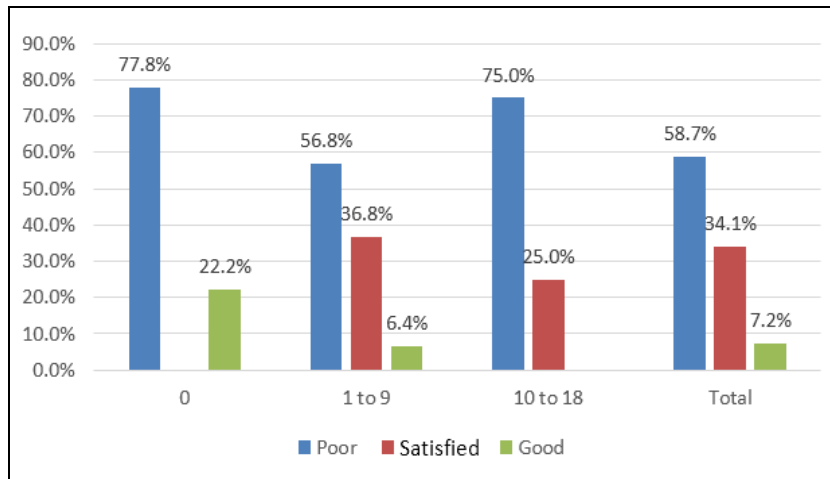

Figure 1. Bar Diagram Showing Distribution of Study Participants according to their Academic Performance and Level of Sleep Disturbance

\section{DISCUSSION}

Results of the study reveal a significant association between sleep disturbance and academic performance in the study group. Necessities of sleep differ from person to person, but 6-8 hours of sleep is considered normal for an adult.[11] The association between sleep disturbances and academic performance among medical students has not been thoroughly elucidated. Curcio[1] reported that sleep poor in 
quality and quantity has a negative correlation with academic performance.

The study found no significant association between level of Day time Sleepiness and academic achievement, though distribution shows that majority of good academic performers have normal day time sleepiness at a lower or higher level (Table 2). These results are consistent with those of Hala Hamed et al., who found no significant difference in CGPA (Cumulative Grade Point Average) between respondents with infrequent day napping and those with frequent day napping $(p=0.632) .{ }^{[12]}$ Other investigators have reported insufficient sleep to be a cause of emotional shakiness, memory loss, day time sleepiness and decreased concentration. ${ }^{[11,13]}$ In the study by Hyder 0 et al which evaluated the effects of chronic sleep deprivation and day time sleepiness in Sudanese medical students the tendency to doze was found to be highest while sitting and reading (88\%) with obvious adverse consequences on their academic performance. [14] Circadian rhythm disorders in the form of delayed sleep phase syndrome marked by significant delays in sleep/wake cycles are common among college students and may result in increased daytime sleepiness.[15] Sleep deprivation is common in medical training and the high academic load and anxiety regarding examinations leading to use of central nervous system stimulants to delay sleep at night may be other causes of daytime sleepiness in medical students which hamper their academic performance.

This study did not find a significant association between sleep quality assessed by PSQI and academic performance [Table 1]. A study conducted in the United States of America reported that the sleep quality measured by PSQI was significantly worse in medical students compared to a healthy adult sample.[16] Chen et al. states that many different variables in the students' sleep environment, such as intrusive light or noise, may have an effect on their quality of sleep.[17] Though this may be a significant factor for students residing at hostels away from home, academic achievement may be as well determined by other factors such as discipline in attending classes, concentration, motivation and time management, which differs among students, which may explain the findings of the present study. This study also did not find an association between self-reported subjective sleep quality and academic performance in the study participants. This may be because the students did not consider a few nights of sleep deprivation due to an impending stress like examination to be equivalent to insomnia. However, previous studies have shown that there is an imperfect, but strong, relation between subjective evaluation of sleep and objective polysomnography measurements.[18]

A significant association between sleep disturbance and level of academic achievement was found in the present study [Table 4]. Among the students with high level of sleep disturbance $75 \%$ showed poor academic performance. Study by Datta A et al. revealed that students who got average mark in last semester exam were most affected with disturbed sleep $(66.3 \%)$ followed by students who got good marks $(53.5 \%)$ and poor marks $(50 \%)$ which was statistically significant.[19] Lund $\mathrm{HG}$ et al reports that hyperarousal of autonomic nervous system and overactivation of hypothalamic-pituitary-adrenal axis can predispose; stressful events such as examinations and relationship problems can precipitate, and rumination and worry can perpetuate the sleep problems.[20] The present study, with 71 female and 67 male students revealed a significant association between gender and academic achievement, with the female students having better academic achievement, but no significant difference in level of sleep disturbance was found between female and male students. A survey conducted by Giri P, Baviskar M, Phalke D among 150 Indian medical students found that sleep quality was better in females than in males.[21]

The sleep-wake cycle of medical students is characterized by insufficient sleep duration, delayed sleep onset, and occurrence of napping episodes during the day.[22] In India, Sivagnanam G and co-workers studied the knowledge, belief, and practice of sleep hygiene among final year medical students of six medical colleges of Tamil Nadu; and found inadequate knowledge and many misconceptions regarding sleep.[23] Erratic sleep schedule and sleep deprivation can cause grave psychologic and health consequences while optimized sleep pattern improves the neuro-cognitive and academic performance of students.[1] The present study supports the findings of many other investigations into the association of sleep quality with academic performance among medical students. Screening of students for preventable and treatable causes of sleep deprivation and excessive daytime sleepiness could improve their academic performance and overall wellbeing. This study has some limitations, such as the relatively small sample size of 138 medical students and the relatively short duration of the study. Errors committed by students due to carelessness and forgetfulness while answering the questionnaire could be another limiting factor. Suggestions for future studies would be a larger sample size that includes more academic years as possible, with a similar representation of both genders.

\section{CONCLUSIONS}

Disturbances in sleep rhythm are a problem in present day medical student and is detrimental to their academic achievement. The need of implementing education on sleep hygiene to medical students should be looked into.

\section{REFERENCES}

[1] Curcio G, Ferraraa M, De Gennaro L. Sleep loss, learning capacity and academic performance. Sleep Medicine Reviews 2006;10(5):323-37.

[2] Azad MC, Fraser K, Rumana N, et al. Sleep disturbances among medical students: a global perspective. J Clin Sleep Med 2015;11(1):69-74.

[3] Ahrberg $K$, Dresler $M$, Niedermaier $S$, et al. The interaction between sleep quality and academic performance. J Psychiatr Res 2012;46(12):1618-22.

[4] Sweileh WM, Ali IA, Sawalha AF, et al. Sleep habits and sleep problems among Palestinian students. Child Adolesc Psychiatry Ment Health 2011;5(1):25.

[5] Gomes AA, Tavares J, de Azevedo MH. Sleep and academic performance in undergraduates: a multimeasure, multi-predictor approach. Chronobiol Int 2011;28(9):786-801. 
[6] Gilbert SP, Weaver CC. Sleep quality and academic performance in university students: a wake-up call for college psychologists. Journal of College Student Psychotherapy 2010;24(4):295-306.

[7] Smith C. Sleep states, memory processing and dreams. Sleep Med Clin 2010;5(2):217-28.

[8] Killgore WD. Effects of sleep deprivation on cognition. Progress in Brain Research 2010;185:105-29.

[9] Aldabal L, Bahammam AS. Metabolic, endocrine and immune consequences of sleep deprivation. The Open Respiratory Medicine Journal 2011;5:31-43.

[10] John's MW. Rethinking the assessment of sleepiness. Sleep Med Rev 1998;2(1):3-15.

[11] Kazim M, Abrar A. Sleep patterns and academic performance instudents of a medical college in Pakistan. KUST Med J 2011;3(2):57-60.

[12] Hamed H, Miskey A, Alkurd R, et al. The effect of sleeping pattern on the academic performance of undergraduate medical students at Ajman University of Science and Technology. IOSR Journal of Pharmacy 2015;5(6):30-3.

[13] Rocha CRS, Rossini S, Reimao R. Sleep disorders in highschool and pre-university students. Arq Neuro-Psiquiatr 2010;68(6):903-7.

[14] Mirghani HO, Ahmed MA, Elbadawi AS. Daytime sleepiness and chronic sleep deprivation effects on academic performance among the Sudanese medical students. Journal of Taibah University Medical Sciences 2015;10(4):467-70.

[15] Buboltz WC Jr, Brown F, Soper B. Sleep habits and patterns of college students: a preliminary study. Journal of American College Health 2001;50(3):131-5.
[16] Brick CA, Seely DL, Palermo TM. Association between sleep hygiene and sleep quality in medical students. Behav Sleep Med 2010;8(2):113-21.

[17] Chen T, Wu Z, Shen Z, et al. Sleep duration in Chinese adolescents: biological, environmental and behavioral predictors. Sleep Medicine 2014;15(11):1345-53.

[18] Loayza HMP, Ponte TC, Carvalho CG, et al. Association between mental health screening by self-report questionnaire and insomnia in medical students. Arq Neuropsiquiatr 2001;59(2-A):180-5.

[19] Datta A, Nag K, Karmakar N, et al. Sleep disturbance and its effect on academic performance among students of a medical college of Tripura. Int J Community Med Public Health 2019;6(1):293-8.

[20] Lund HG, Reider BD, Whiting AB, et al. Sleep patterns and predictors of disturbed sleep in a large population of college students. J Adolesc Health 2010;46(2):124-32.

[21] Giri P, Baviskar M, Phalke D. Study of sleep habits and sleep problems among medical students of Pravara Institute of Medical Sciences Loni, Western Maharashtra, India. Ann Med Health Sci Res 2013;3(1):51-4.

[22] Ng EP, Ng Dk, Chan CH. Sleep duration, wake/sleep symptoms, and academic performance in Hong Kong Secondary School Children. Sleep Breath 2009;13(4):357-67.

[23] Sivagnanam G, Thirumalaikolundusubramanian $P$, Sugirda P, et al. Study of the knowledge, beliefs and practice of sleep among medical undergraduates of Tamilnadu, India. Med Gen Med 2004;6(4):5. 